\title{
Afferent Neurourology: A Novel Paradigm
}

\author{
J. Quentin Clemens* \\ Department of Urology, University of Michigan Medical Center, Ann Arbor, Michigan
}

The term "afferent neurourology" is introduced to describe the study of sensory processing related to the genitourinary tract. Urologic disorders that are characterized by abnormal sensory processing are reviewed, and unique challenges to our understanding of these disorders are described. A paradigm which separates afferent urologic disorders from efferent disorders and structural abnormalities is presented. Neurourol. Urodynam. 29:S29-S31, 2010.

(c) 2010 Wiley-Liss, Inc.

Key words: chronic prostatitis; interstitial cystitis; orchalgia; overactive bladder

\section{INTRODUCTION}

The field of neurourology may be succinctly defined as the study of normal lower urinary tract neurophysiology, as well as functional urologic abnormalities resulting from neurologic disease or injury. Many neurologic disorders can adversely affect urinary tract function, including congenital disorders (spina bifida), systemic diseases (multiple sclerosis), and localized injuries (cerebrovascular accident, traumatic spinal cord injury). ${ }^{1}$ The urologic management of these patients focuses on improving continence and preventing upper urinary tract complications. Management principles are well established, and include a variety of non-surgical and surgical techniques to reduce reflex detrusor activity and maintain low bladder storage pressures. ${ }^{2,3}$ These techniques are primarily focused on identifying and modulating motor (efferent) neurologic activity.

There exists an entirely different group of "urologic" abnormalities which are characterized by pain and/or urinary urgency. A variety of diagnoses can be assigned to these symptoms (Table I). However, these diagnostic labels are largely based on clinical criteria rather than on objective criteria. Therefore, such diagnoses are likely to have poor reliability and validity. Many of these disorders are characterized as infectious or inflammatory conditions, ${ }^{4,5}$ even though current evidence suggests that neither infection nor inflammation is involved in the etiology of the symptoms. Instead, it may be more appropriate to consider these conditions as urologic manifestations of sensory neurologic dysfunction.

\section{PROPOSED TERMINOLOGY}

The term afferent neurourology is proposed. This term refers to the field of study concerned with the processing of sensory information related to the genitourinary (GU) tract. This includes sensory processing within the GU tract as well as sensory data from the GU tract which is processed elsewhere within the peripheral and central nervous system. Furthermore, it is acknowledged that many afferent signals are not perceived at the conscious level but they still play a vital role in afferent neurourology as it relates to lower urinary tract physiology. Inclusive in this concept is that abnormal processing of sensory information related to the GU tract results in distressing symptoms and healthcare seeking. The term afferent urologic disorders is used to describe the various clinical terms that are often employed to categorize these symptoms (Table I). Certain clinical disorders (e.g., vulvodynia, endometriosis) are excluded, as they are typically not managed by urologists. However, such disorders could potentially be included in a broader term such as "Afferent Pelvic Disorders."

\section{AFFERENT NEUROUROLOGY-SYMPTOMS}

Abnormal processing of sensory information related to the GU tract results in pain and/or urgency. The International Association for the Study of Pain (IASP) defines pain as an "unpleasant sensory or emotional experience associated with actual or potential tissue damage, or described in terms of such damage." From a urologic standpoint, pain can be from bladder or non-bladder sources. This categorization is relevant because bladder pain is significantly more difficult to describe and characterize than non-bladder pain (see below). The International Continence Society defines urgency as the "sudden compelling desire to pass urine, which is difficult to defer."7 It could potentially be argued that this commonly accepted definition of urgency may in fact meet the IASP criteria for pain presented above. However that interpretation is certainly open to debate, and the inclusion of urgency as a separate symptom component within the afferent neurourology paradigm seems to be appropriate at this time.

Conflicts of interest: Dr. Clemens-Equity interest: Merck; Consultant: Wiley, Pfizer; Proctor: Medtronic.

Roger Dmochowski led the review process.

${ }^{*}$ Correspondence to: J. Quentin Clemens, MD, MSCI, Department of Urology, University of Michigan Medical Center, 1500 East Medical Center Drive, Ann Arbor, MI 48109-5330.E-mail: qclemens@umich.edu

Received 13 May 2009; Accepted 23 June 2009

Published online 15 April 2010 in Wiley InterScience

(www.interscience.wiley.com)

DOI 10.1002/nau.20792 
TABLE I. Afferent Neurourology-Disorders

Interstitial cystitis/painful bladder syndrome/bladder pain syndrome Bladder pain, pressure, or discomfort

Chronic prostatitis/chronic pelvic pain syndrome (NIH Type III prostatitis) Penile pain, perineal pain, pain with ejaculation

Overactive bladder

Urgency \pm frequency \pm nocturia

Orchalgia/chronic epididymitis

Unilateral scrotal/testicular pain

Dyspareunia

Pain with intercourse

Nocturia and urinary frequency are additional bothersome symptoms that are a frequent cause of urology clinic visits. However, these two symptoms are actually behaviors that are driven by urinary urgency, bladder pain, and/or many other factors. ${ }^{8}$ For instance, frequency and nocturia may occur in individuals with completely normal urinary tracts who drink excessive amounts of fluid. For this reason, nocturia and frequency are not included as symptom components within the afferent neurourology paradigm.

\section{BLADDER PAIN VERSUS URGENCY}

The distinction between various afferent urologic disorders is not always clear. For instance, the criteria used to differentiate interstitial cystitis/painful bladder syndrome (IC/PBS) from overactive bladder (OAB) have received considerable attention. ${ }^{9,10}$ The hallmark symptom of IC/PBS is pain that is referable to the bladder, ${ }^{7,11}$ while the hallmark symptom of $\mathrm{OAB}$ is urgency. ${ }^{7}$ However, some individuals with a diagnosis of IC/PBS deny the presence of pain, but instead refer to their symptoms as "pressure" or "discomfort" or "urgency."12,13 This observation has caused some to differentiate between "urgency" (which would identify OAB), and "persistent urge to void" (which would be more consistent with IC/PBS symptoms). ${ }^{11}$ Others have stated that the urgency in $O A B$ is characterized by fear of leakage, while the urgency of IC/PBS is due to pain, pressure, or discomfort. ${ }^{9,10}$ The problem with these categorization efforts is that there will invariably be individuals who defy categorization, regardless of the category that is chosen. For example, in a study of 180 women with incident IC/PBS diagnoses, fully $21 \%$ reported urinary urgency due to a fear of leakage, and an additional $9 \%$ indicated no urgency at all. ${ }^{14}$ Also, in the Interstitial Cystitis Database study, approximately $15 \%$ of individuals with a clinical diagnosis of IC/PBS had urodynamic evidence of detrusor overactivity. ${ }^{15}$ Finally, it is the author's personal observation that some individuals with classic OAB symptoms will describe their urgency as "painful." Until meaningful patient subgroups can be differentiated based on objective data that are tied to a known pathophysiologic process, it may be preferable to avoid arbitrary diagnoses and instead focus on symptom descriptions. ${ }^{16,17}$

\section{AFFERENT, EFFERENT, AND STRUCTURAL ABNORMALITIES}

Conceptually, afferent urologic disorders can be differentiated from efferent and structural abnormalities (Table II). Examples of efferent (motor) abnormalities include detrusor overactivity/urge incontinence, detrusor sphincter dyssynergia, diminished bladder compliance (due to increased detrusor muscle tone), detrusor failure, and dysfunctional voiding (pseudodyssynergia). Examples of structural abnormalities include stress urinary incontinence, pelvic prolapse, dimin-
TABLE II. Afferent, Efferent, and Structural Abnormalities

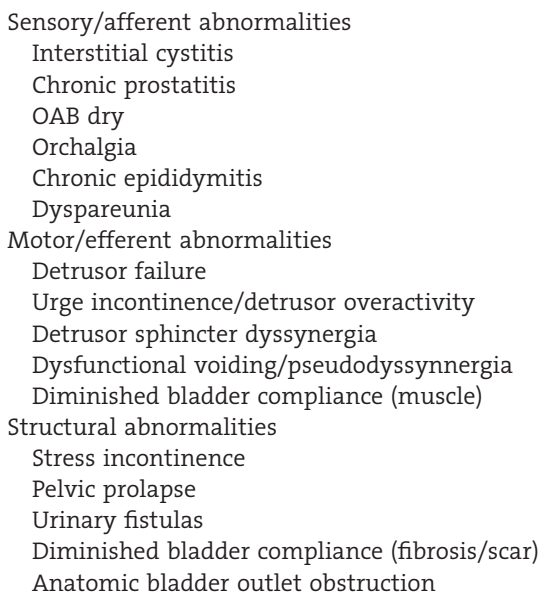

ished bladder compliance (due to bladder wall fibrosis), urinary fistulas, and anatomic bladder outlet obstruction.

There is clearly a relationship between the afferent symptom of urgency and the efferent condition of urge incontinence/detrusor instability, but this relationship is not well understood. For instance, urge incontinence/detrusor overactivity does appear to include dysfunction of the prefrontal cortex and/or abnormal afferent signaling in at least some patients. The condition $O A B$ is often subcategorized into "OAB dry" (urgency without urge incontinence) and "OAB wet" (urgency with urge incontinence). These two subgroups are considered part of an $\mathrm{OAB}$ disease spectrum, but it is not known if they in fact share the same underlying pathophysiology. It is also unclear to what extent those with "OAB dry" progress to "OAB wet." Furthermore, the mechanism respon-

TABLE III. Medline Citations as of September 2008

Prostate cancer

33,403

Urinary tract infections

26,178

Urinary incontinence

21,330

$\mathrm{BPH} /$ prostatic hyperplasia

16,347

Erectile dysfunction/impotence

14,303

Bladder cancer

13,024

Kidney calculi

12,639

Renal cell carcinoma

12,550

Prostatitis

4283

Dyspareunia

1954

Interstitial cystitis

1430

Overactive bladder

1119

"Pain" and "testis"

606

Orchalgia

13 


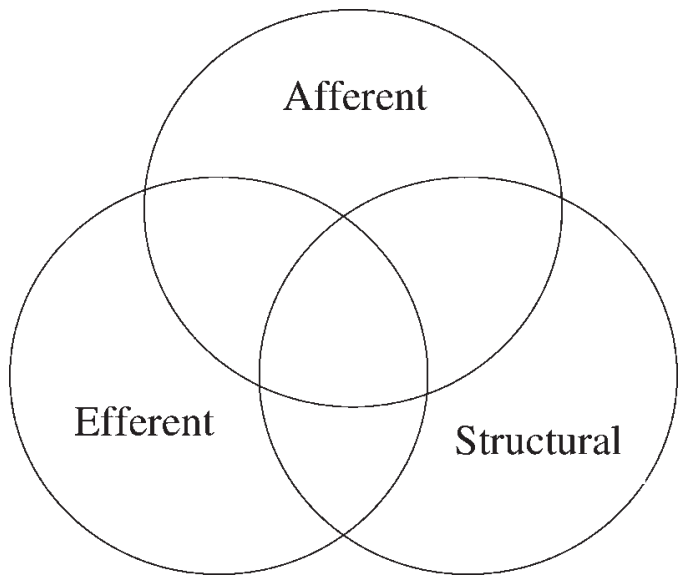

Fig. 1. Overlap of urologic conditions.

sible for converting the afferent symptom of urgency to the efferent symptom of urge incontinence is not well understood.

It is notable that each of the efferent and structural abnormalities has an objective diagnostic test which can be used to confirm the diagnosis and quantify its severity. Conversely, the afferent urologic disorders currently have no objective tests which can confirm the diagnosis, identify specific subgroups of patients, or provide prognostic information. This may be one reason why these disorders have received little attention in the literature (Table III). Urgency and pain could theoretically be caused by abnormal sensory processing within the GU tract or by abnormal processing of sensory data from the GU tract, or a combination of both.

\section{OVERLAP OF AFFERENT, EFFERENT, AND STRUCTURAL ABNORMALITIES}

Clinicians will quickly recognize that multiple afferent, efferent, and structural disorders may be present in an individual patient (Fig. 1). For example, certain women may present with stress incontinence (structural), poor detrusor contractility (efferent), and bladder pressure/pain (afferent). Men may present with anatomic bladder outlet obstruction due to prostatic hyperplasia (structural), detrusor overactivity (efferent), and perineal pain (afferent). The clinical management is fairly straightforward in patients with symptoms in a single category (afferent, efferent, or structural), but becomes increasingly complex as they manifest symptoms in additional categories. It seems reasonable to conclude that effective patient management requires recognition of this overlap when it occurs.

\section{CONCLUSION}

The term "afferent neurourology" can be used to describe the processing of sensory information related to the GU tract. Abnormal sensory processing (within the GU tract or centrally) causes symptoms of pain and urinary urgency. Patients with these symptoms are often diagnosed with "interstitial cystitis," "prostatitis," or "overactive bladder" although these diagnoses are fraught with problems. These afferent urologic symptoms often overlap with efferent symptoms and structural abnormalities, and effective patient management requires an awareness of this.

\section{REFERENCES}

1. Wein AJ. Lower urinary tract dysfunction in neurologic injury and disease. In: Wein AJ, Kavoussi LR, Novick AC, Partin AW, Peters CA, editors. CampbellWalsh urology. Philadelphia: Saunders; 2007. pp 2011-45.

2. Wang SC, McGuire EJ, Bloom DA. A bladder pressure management system for myelodysplasia - Clinical outcome. J Urol 1988;140:1499-502.

3. McGuire EJ, Noll F, Maynard F. A pressure management system for the neurogenic bladder after spinal cord injury. Neurourol Urodyn 1991;10:22330 .

4. Nickel JC. Inflammatory conditions of the male genitourinary tract: Prostatitis and related conditions, orchitis, and epididymitis. In: Wein AJ, Kavoussi LR, Novick AC, Partin AW, Peters CA, editors. Campbell-Walsh urology. Philadelphia: Saunders; 2007. pp 304-29.

5. Hanno PM. Painful bladder syndrome/interstitial cystitis and related disorders. In: Wein AJ, Kavoussi LR, Novick AC, Partin AW, Peters CA, editors. Campbell-Walsh urology. Philadelphia: Saunders; 2007. pp 330-70.

6. Merskey H, Bogduk N, editors. Classification of chronic pain: Descriptions of chronic pain syndromes and definitions of pain terms, 2nd edition. Seattle: IASP Press; 1994.

7. Abrams P, Cardozo L, Fall M, et al. The standardization of terminology of lower urinary tract function: Report from the standardization sub-committee of the International Continence Society. Neurourol Urodyn 2002;21:16778 .

8. Appell RA, Sand PK. Nocturia: Etiology, diagnosis, and treatment. Neurourol Urodyn 2008;27:34-9.

9. Abrams P, Hanno P, Wein A. Overactive bladder and painful bladder syndrome: There need not be confusion. Neurourol Urodyn 2005;24:149-50.

10. Abrams P. Urgency: The key to defining the overactive bladder. BJU Int 2005;96:1-3.

11. van de Merwe JP, Nordling J, Bouchelouche P, et al. Diagnostic criteria, classification, and nomenclature for painful bladder syndrome/interstitial cystitis: An ESSIC proposal. Eur Urol 2008;53:60-7.

12. Bogart LM, Berry SH, Clemens JQ. Symptoms of interstitial cystitis, painful bladder syndrome, and similar diseases in women: A systematic review. J Urol 2007;177:450-6.

13. Sirinian E, Azevedo K, Payne CK. Correlation between 2 interstitial cystitis symptom instruments. J Urol 2005;173:835-40.

14. Greenberg P, Brown J, Yates T, et al. Voiding urges perceived by patients with interstitial cystitis/painful bladder syndrome. Neurourol Urodyn 2007;27: 287-90.

15. Simon L, Landis JR, Erickson DR, et al. The interstitial cystitis data base study: Concepts and preliminary baseline descriptive statistics. Urology 1997:49:64-75.

16. Baranowski A, Berger RE, Fall $M$, et al. A new classification is needed for pelvic pain syndromes-Are existing terminologies of spurious diagnostic authority bad for patients? J Urol 2006:175:1989-90.

17. Clemens JQ, Markossian TW, Meenan RT, et al. Overlap of voiding symptoms, storage symptoms and pain in men and women. J Urol 2007;178:1354-8. 